\title{
CODE OF GOOD MILLING PRACTICE IN ENHANCING SUSTAINABLE PALM OIL PRODUCTION
}

\section{NURUL FATHIAH MOHD SHUKRI*; AINIE KUNTOM*; MOHD FIKRY JAMALUDDIN; MUHAMMAD NIZAMUDIN MOHAMED* and N RAVI MENON*}

\begin{abstract}
Fresh fruit bunches (FFB) are continuously being produced throughout the year, hence the mill also needs to operate continuously to process them. Compared to other oil crops, oil palm is more productive and produces the highest oil yield per hectare. However, like any other industry, palm oil processing can also have adverse impact on the environment. Therefore, this article focuses on the operation of palm oil mill by addressing the impact on quality, food safety and some sustainability elements as measurable parameters when gauging the impacts of the processing operation. This article also emphasises the implementation of the Malaysian Palm Oil Board Code of Good Milling Practices (MPOB CoPM) as a guideline for the mills in readiness for sustainability certification under the Malaysian Sustainable Palm Oil (MSPO)/Roundtable on Sustainable Palm Oil (RSPO). Under sustainability, the three well-established elements will be examined and they are environmental protection, social responsibility and economic practice. The palm oil processing plant should produce palm oil that can be classified as sustainable palm oil, otherwise it may not be able to enjoy global marketability.
\end{abstract}

Keywords: sustainability, palm oil milling, code of practices.

Received: 28 June 2019; Accepted: 23 October 2019; Published online: 10 September 2020.

\section{INTRODUCTION}

The oil palm was introduced to Malaya (now known as Malaysia) in 1870s as an ornamental plant and in 1917, first commercially planted at the Tennamaran Estate, Selangor (Balu et al., 2018). Malaysia is now the second largest producer of palm oil in the world, after being overtaken by Indonesia in 2006 (Schuster Institute for Investigative Journalism 2012). In Malaysia, about 5.85 million hectares of land are under oil palm cultivation, with 2.73 million hectares in Peninsular Malaysia and 3.12 million hectares in Sabah and Sarawak (Kushairi et al., 2019). The oil palm industry is a well-

\footnotetext{
Malaysian Palm Oil Board,

6 Persiaran Institusi, Bandar Baru Bangi,

43000 Kajang, Selangor, Malaysia.

E-mail: nurul.fathiah@mpob.gov.my
}

known agricultural industry in terms of economic benefits. It comprises of upstream, midstream and downstream sectors. This article will focus on the impact of implementation of the Malaysian Palm Oil Board Code of Good Milling Practices (MPOB CoPM) by the midstream sector, namely the palm oil mill as a step towards sustainability practices and addressing current issues on food safety and process developed contaminants.

\section{MPOB CODE OF PRACTICES}

The MPOB Code of Practices (MPOB CoP) is one of the certification schemes developed by MPOB. It is intended to assist the industry to fulfill their responsibilities on the assurance of food safety, quality standards and sustainability of the operations. The implementation of MPOB 
CoPM will be the first step for the mill to establish the appropriate documentation to address the sustainability requirements prior to certification under the Malaysian Sustainable Palm Oil (MSPO)/ RSPO. From the MPOB CoP auditing, it was found that most private mills which have implemented MPOB CoPM have less problems to comply with sustainability requirements. The requirement of the MPOB CoPM includes document traceability, mill construction and design, efficient operations, maintenance, food safety requirements, quality control, hygiene conditions, pest control, welfare, environment impact, storage, handling, and transportation. The $\mathrm{CoP}$ provides guidance to maintain food safety and quality along the whole oil palm supply chain. The code of practice is not a law, but it should be followed unless there is an alternative course of action that achieves the same or better standards.

When a mill follows closely the requirements in the MPOB CoPM and audited against these requirements by competent auditors, the mills have shown that crude palm oil (CPO) produced meets with the quality specification and food safety standard. The three factors on food safety are chemical, biological and physical contamination. Currently, the issues on food safety and sustainability are high in the priority list of the mills.

For the CPO to be acceptable by the consumers or refiners it has to be certified sustainably produced, either by MSPO, RSPO or the International Sustainability and Carbon Certification (ISCC) because the importing countries require the palm oil to be sustainably produced and safe for human consumption.

\section{PROCESSING}

Currently, Malaysia has a total of 451 mills that produce about 19.52 million tonnes of CPO and 4.86 million tonnes of palm kernel (Kushairi et al., 2019). The capacity of the mills varies from 30-90 $t$ fresh fruit bunch (FFB) hr ${ }^{-1}$, but a few of them may exceed this range up to $100 \mathrm{thr}^{-1}$. Palm oil is extracted from the FFB by mechanical processes. Solvent extraction is also possible but it introduces another issue of food safety due to solvent as an extractor and hence not commonly practised in Malaysia. The flow diagram of the processing steps in a palm oil mill is shown in Figure 1.

\section{FFB}

Freshly harvested FFB are normally delivered to the mills for processing within $24 \mathrm{hr}$ in order to preserve the quality of fruits. It is not always possible to perform this task due to a few obstacles such as unexpected rain in the afternoon. If the plantations implement the Good Agricultural Practice (GAP) as defined under the MPOB CoP, there should be 100\% ripe grade $\mathrm{FFB}$, which not only leads to a significant increase in mill oil extraction rate (OER) but also improves the quality of oil produced.

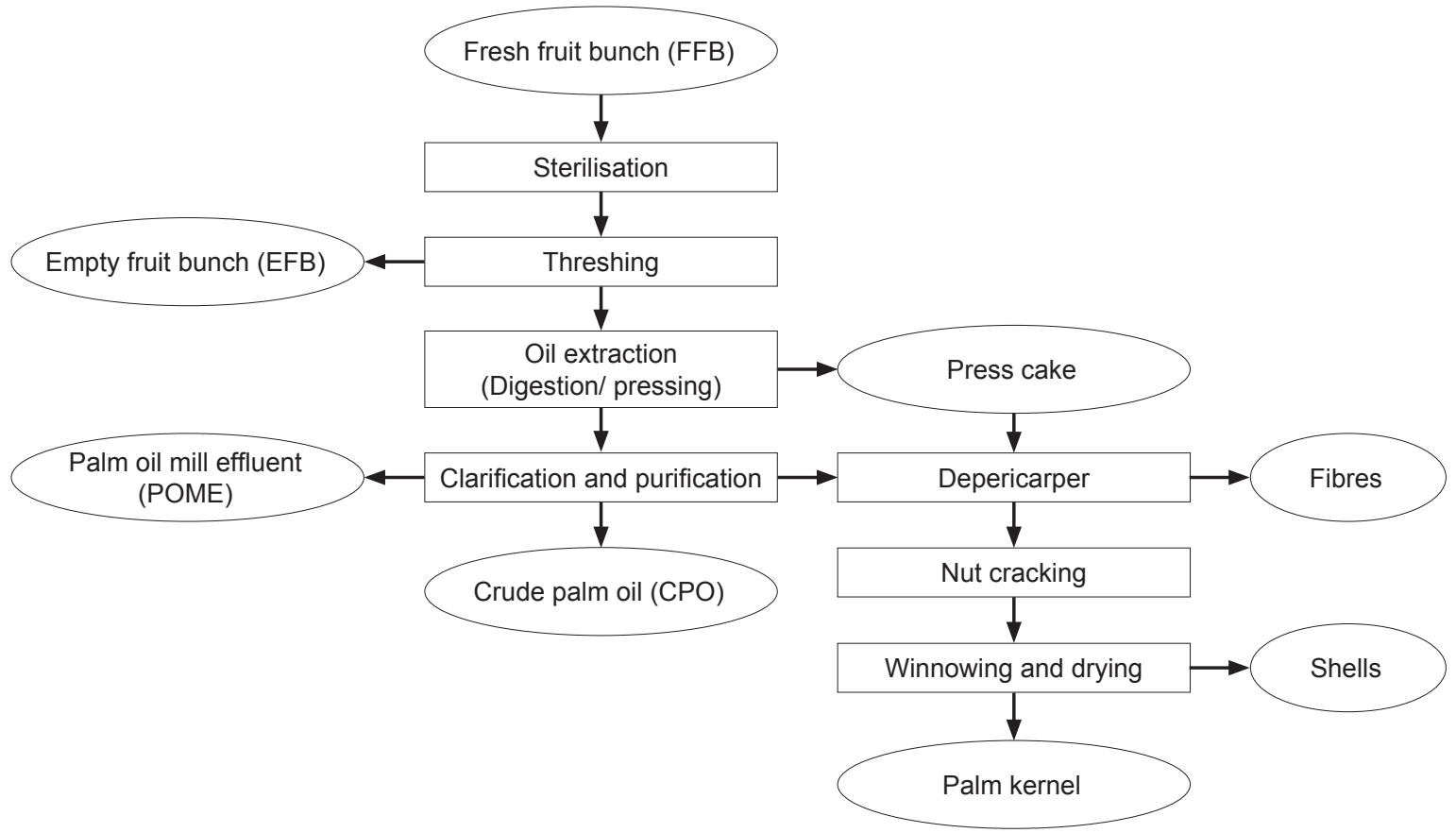

Figure 1. Flow diagram of the processing in palm oil mill. 


\section{Sterilisation}

Sterilisation is a process of cooking FFB with low pressure steam at $300 \mathrm{kPa}$ using a steam receiver that receives exhaust steam from a non-condensing steam turbo generator plant. The pressure cooking also sterilises FFB by arresting the rise of free fatty acids (FFA) caused by lipolytic enzymes. The objective of the sterilisation process is to deactivate lipolytic enzymes, which are responsible for the breakdown of lipids into FFA and also assists in loosening the fruits from the bunches (Parveen et al., 2010). The maximum sterilising pressure is usually about $300 \mathrm{kPa}$ with duration of about $90 \mathrm{~min}$ to cook the palm fruits. The most usual form of the steriliser regime is the triple peak sterilisation.

The first two peak pressures are $200 \mathrm{kPa}$ and $250 \mathrm{kPa}$, respectively and the third peak pressure is $300 \mathrm{kPa}$. The three peaks of steam admission and blow-off are for evacuating the air contained in the steriliser. The air removal improves the heat transfer from steam to bunches as the air is a poor thermal conductor. Despite the three peaks of steam admission and deaeration, some residual air trapped within the bunches still remained after the deaeration process. This effectively means that the steriliser contains FFB bunches with a mixture of air and steam in the steel containers.

Therefore, the pressure gauge attached to the steriliser does not indicate the pressure of the steam but the sum of the partial pressure of steam and the partial pressure of air according to the Dalton's Law of Partial Pressures. If the pressure gauge shows a reading of $300 \mathrm{kPa}$, it may mean a steam pressure of $150 \mathrm{kPa}$ and an air pressure of $150 \mathrm{kPa}$. At $150 \mathrm{kPa}$, the saturation temperature of the steam is only $127.4^{\circ} \mathrm{C}$ instead of $143.6^{\circ} \mathrm{C}$ as expected in the steriliser based on the assumption that thermometer indicates a steam pressure of 300 $\mathrm{kPa}$. After the third peak attains the desired $300 \mathrm{kPa}$ pressure, the right approach is to shut-off the steam inlet valve to promote the steam condensation, thereby releasing more heat for heat transfer. This aspect of thermodynamics indicates the efficient use of steam, which is considered as an important component of sustainability.

\section{Threshing}

The bunch undergoes threshing (also known as stripping) in a rotary drum during which the fruits (also called fruitlets) are separated from the fruit bunch after stripping. After stripping the bunches, the resulting bunch is called an empty fruit bunch (EFB) or bunch refuse. The thresher drum rotates at a speed of $0.32 \mathrm{~Hz}(19 \mathrm{rpm})$. The interior of the drum is fitted with six lifting bars, each of which is about $60 \mathrm{~cm}$ and is welded at an angle to the thresher body so that the segments are angled to be part of a spiral. The purpose is to lift the bunches to about three-quarter way up the drum and simultaneously move forward by $30 \mathrm{~cm}$ as the bunches drop down. Bunches traverse six times undergoing threshing and at each drop move forward by about $30 \mathrm{~cm}$. The impact causes the fruits to strip. The separated fruits pass through the slotted body of the thresher drum into a conveyor that conveys the fruits into a fruit elevator for delivering them into the digesters. The fruit elevator drive gear is located at the top and when greasing is applied on the gear drive, the grease used should be of food grade to ensure food safety of the CPO and to prevent contamination of the hydrocarbon-based grease. This is a serious non-compliance under food safety requirements.

\section{Digestion/Pressing}

Sterilisation itself conditions the fruits by raising the temperature of the fruits to $130^{\circ} \mathrm{C}$ for not less than $30 \mathrm{~min}$. The function of the digester is to digest the fruits, causing the cells to rupture and release the oil under the action of the stirrer blades that rotate an optimum speed of $0.43 \mathrm{~Hz}$ (26 rpm) (PORIM, 1994). Failure to comply with the established values may compromise milling efficiency and induce product losses. The pressing method is commonly used to extract crude oil from digested palm fruit, and the press plate pressure should not exceed $2 \times 10^{6} \mathrm{~Pa}$ to reduce the nut breakage. The nut breakage should not exceed $5 \%$.

\section{CPO Dilution and Related Sustainability Issues}

Most Malaysian mills practise addition of water to the press liquor and this process produces more effluent than needed. Any volume of added water has to be removed as waste water. Water addition up to $50 \%$ increases the CPO viscosity to a maximum, leading to a reduction in separation efficiency. For sustainability initiative, there should not be excessive water dilution as it will eventually act as an effluent. The press liquor is fed directly into a decanter where oil and solids are separated out with minimum processing steps. The $\mathrm{CPO}$, after addition of water, passes through a double deck vibrating screen with a 60/40 mesh or 60/30 mesh or any other configuration based on needs of the mills. After this step, the diluted crude oil may or may not pass through a de-sander to remove the sand accompanying the fruit bunches. Sand contamination in CPO is highly undesirable, positively harmful and costly occurrence in any palm oil mill. The sand-laden CPO will have a major impact on the machinery metal wastage due to its highly erosive nature and on physical contaminant under food safety. If the good practices are implemented by the management, the issue of physical contamination can be easily addressed 
since any material made of iron is recommended not to be used in the process. Based on the MPOB CoPM, any material made of iron is avoided to prevent oxidation of the CPO.

\section{Crude Oil Pumping}

One of the MPOB CoPM that should be adopted by the millers is to use the displacement pump instead of centrifugal pump since the high speed of the centrifugal pump may fragment oil particles into submicron sizes rendering them incapable of rising up in the clarification tanks. The oil particles lack of buoyancy to rise up during the process will eventually introduce wastage as they will be lost through waste water. The oil that is lost in the waste water will be responsible for the high biochemical oxidation demand (BOD) of the waste water and at the same time directly impacting the environment waste water. The level of BOD in waste water is regulated by Department of Environment (DOE).

\section{Clarification}

At the clarification station, the process is purely static and does not contribute to any known pollution. However, oversized clarifiers with retention time exceeding $3 \mathrm{hr}$ may contribute towards a diminishing Deterioration of Bleachability Index (DOBI) value for the CPO due to the prolonged duration of heating within the clarifier. Temperatures above $90^{\circ} \mathrm{C}$ also will be detrimental to oil quality in terms of lowering the DOBI value.

\section{Nut/Fibre Separation}

The function of the press cake breaker conveyor is to break the well-compacted press cake (comprising of the press cake made up of nuts and fibre) produced by the pressing of digested fruits to extract the oil. The earlier version of the press cake breaker conveyor equipped with paddle arms to break the cake have now given way to a simple conveyor that serves only to transport the press cake to the depericarp column. The conveyor is usually $15-20 \mathrm{~m}$ in length and rotating at $0.92 \mathrm{~Hz}(55 \mathrm{rpm})$. The length is important because the compacted press cake has to be loosened during the passage of the press cake to separate the nuts when the press cake is discharged into the depericarp column. Experiments have shown that at least $1.5 \mathrm{~Hz}(90$ $\mathrm{rpm}$ ) is required for conveyors with a diameter of $40-50 \mathrm{~cm}$ and at least $1.23 \mathrm{~Hz}(75 \mathrm{rpm})$ for conveyors with a diameter of $60 \mathrm{~cm}$ (PORIM, 1994).

The press cake from the conveyor is discharged into the separation column with an entry point one-third higher than the top of the column. The separation velocity can be changed by pushing in or out the switch on the velocity box. The separation velocity is usually set between 12 and $16 \mathrm{~ms}^{-1}$. The separated nuts drop down into the polishing drum while the separated fibres in the separating column are U-turned and carried by the long ducting for discharging into the fibre cyclone through the draft created by the induced draft fan located at the fibre cyclone outlet. The ID fan that creates the suction will also suck the fine dust particles from the press cake and discharge it to the open air. This causes considerable air pollution and the free discharge of submicron particles into atmosphere could cause respiratory problems in human beings and as such should be controlled.

\section{Kernel Extraction and Drying}

When entering the ripple mills, the nuts are subjected to grinding and eventually they crack, although not the perfect way, because the percentage of broken kernels is usually more than $25 \%$ when using a ripple mill, which is far from the required $5 \%$. The earlier versions of the centrifugal crackers were able to limit broken kernel to less than 5\% because the nuts were dried for $14 \mathrm{hr}$ before cracking. The industry adopts ripple mill in preference to the centrifugal crackers because the ripple mill could crack the nuts without the pre-heating step. Another advantage of the ripple mill is low maintenance requirement and Rolek is one of the palm nut crackers that was introduced to the industry. The Rolek is used to achieve maximum cracking efficiency of palm nuts and promote better separation of shell and kernel through the production of uniformed and small size shell (Rohaya et al., 2006).

The cracked mixture after the nut cracking operation contains approximately equal proportions of kernel and shell. The difference in their densities is used to separate the two fractions. Two methods are used in the industry to recover grain from the cracked mixture such as hydro-clay bath and hydrocyclone. Both separation systems follow the principle of different kernel and shell densities. In a hydro-cyclone, the cracked mixture is fed into a water bath and the cracked mixture bath is pumped into a cyclone at an angle that is tangential to the cyclone body. The heavy shell is pushed to the periphery of the cyclone, while the lighter kernel is sucked to the centre of the cyclone due to the viscous drag caused by the rotation of the water mass around the vortex tube. The shell is discharged through the cyclone outlet at the bottom while the kernel is discharged at the top exit. Usually two stages of kernel separation cycles work in tandem so that the final kernel is free from shell. The external surface of the kernel is still wet at this stage, but such moisture quickly evaporates. Apart from this external moisture, there is a greater amount of internal moisture, which accounts for about $20 \%$ of the weight of the kernel. 
This moisture is more difficult to remove as it must first diffuse outwards to the surface before it can evaporate, and this process takes time. The objective of drying is to enable storage of the kernel without deterioration due to mold growth and this can be achieved if the moisture content of the kernels is reduced to less than $7 \%$ (PORIM, 1994).

\section{IMPACT OF PROCESS ON ENVIRONMENT}

Air pollution occurs when the atmosphere is contaminated with gaseous, liquid or solid wastes or other by-products that may affect human health, living organisms, environment and plants. The main source of air pollution in palm oil mills is the burning of palm solid wastes as boiler fuel.

\section{Dispersion of Particulate Matters}

Particulate matter or particle pollution is defined as a complex mixture of both organic and inorganic substances, which are divided into two main groups, coarse and fine. The coarse fraction contains larger particles ranging in size from $2.5-10 \times 10^{-6} \mathrm{~m}$. While the fine fraction contains smaller particles having a size of at most $2.5 \times 10^{-6} \mathrm{~m}$. Particulates include dust, fume, mist, smoke, smog and soot. All the terms are defined based on the size of the particles. They have different physical, chemical and electrical properties that affect their rates of settling and contribute to the formation of haze in the atmosphere. Once inhaled, these particles can affect the lung and cause serious health effects to human (WHO, 2003).

Smoke is the emission of airborne solid particulates and liquid particulates and gases resulting from the combustion of materials in the presence of oxygen. When less oxygen is supplied during reheating, the liquid aerosols decompose into tiny carbon particles known as soot. The darkness of the smoke released by palm oil mill boilers is due to the presence of this soot. Owing to its small size, soot particles normally pass through most dust collection devices. The black smoke problem may also be contributed by the use of under-sized boilers, especially in oil mills, inadequate maintenance of the dust control system and improper or overfeeding of boiler fuel.

Atikah et al. (2017) has stated that drop of the drum pressure is caused by the inefficient combustion of the boiler, as seen by the emission of black smoke during combustion. The released black smoke consists of small particles, carbon monoxide, carbon dioxide as well as water vapour, hydrocarbons and more hazardous gases. The emission of black smoke comes from the incomplete combustion of solid fuel. Therefore, to eliminate or mitigate the particulate emissions and black smoke from the palm oil mill boilers, the mills can optimise the engineering design of the furnace for efficient and complete combustion. Besides that, particulate and dust collection devices such as multicyclone collectors, bag filters and electrostatic precipitators shall be installed at the boiler to eliminate the particulate emissions and black smoke. Under sustainability requirements, all precautions have to be taken to comply with MSPO.

\section{Greenhouse Gases}

Greenhouse gases include carbon dioxide, methane, nitrous oxide and other gases that accumulate in the atmosphere and create a heatreflective layer that controls the acceptable earth temperature and sufficient to support life. However, the greenhouse effect results in global warming when the concentration of greenhouse gases (carbon dioxide, carbon monoxide, nitrogen dioxide) in an enclosed space increases and the restriction of heat is easily radiated back into space and this trapped heat will increase the temperature of the surface of the earth.

The palm oil mill also generates greenhouse gases from POME. Seyed et al. (2013) has stated that POME is a by-product of the palm industry and it discharges large amounts of greenhouse gases. The process of treating palm oil waste by anaerobic decomposition produces methane-containing biogas (Reijnders et al., 2006). Although methane emission is lower than carbon dioxide emission, it is considered to be a major greenhouse gas because each methane molecule has 25 times the global warming potential of a carbon dioxide molecule (Land Trust Alliance, 2019).

Greenhouse gases have a negative impact on the environment, such as the possibility of global warming that can cause glacial melting and sea levels rise by a few centimetres. Therefore, it is important to reduce the percentage of the greenhouse gases. In Malaysia, the trend is to reduce the greenhouse gases by installing the biogas capturing equipment. As a result, the greenhouse gases emission rate from mills can be reduced by more than $80 \%$. Besides that, these mills have improved boiler efficiency and raised the rate of palm oil process performance in order to reduce greenhouse gases (Seyed et al., 2013).

\section{FOOD SAFETY OF CPO AND PALM KERNEL}

\section{Pesticide Residue}

Pesticides and herbicides are commonly used in oil palm plantations to control pests such as insects, rodents and weeds. According to Jinius et al. (2001), in order to increase the yield and income, farmers tend to use a variety of pesticides such 
as insecticides, fungicides, herbicides and others. However, the uncontrolled use of pesticides in plantation will affect the food safety of oil palm products and safety of the workers. Hence, the application has to follow the recommended usage of pesticides.

Certification scheme and verification of implementation are needed to ensure the compliances. Under the requirement of the MPOB CoPM, clause 4.29 .3 suggests the need to analyse for pesticide residue (MPOB, 2018). This clause states the following:

i) The frequency of pesticide residue analysis shall be based on a risk assessment and taking into consideration its intended use.

ii) The test results should be traceable to the crop producer and the production site.

iii) The laboratories used for residue testing shall be accredited by a competent accreditation authority to obtain good laboratory standards (e.g. MS ISO/IEC 17025).

iv) Preventive and corrective action plans shall be in place if the maximum residue level (MRL) is exceeded.

The Sixteenth Schedule of the Malaysian Food Act (1983) states that the food shall not contain the pesticides in proportion greater than the maximum permitted proportion in MRL. Therefore, the producers and manufactures have to comply with this regulation (AGC, 2009).

According to the United States Environmental Protection Agency (USEPA), the Food Quality Protection Act (FQPA) requires that all pesticides used on crops must meet the FQPA's stringent safety standard. The FQPA standard needs to ensure that the use of pesticides on food is safe for infants and children as well as adults (USEPA, 2019). Therefore, based on strict FQPA standards, major scientific improvements, and increased use of safer, less toxic pesticides, EPA will continue to evaluate the safety of each pesticide every 15 years, leading to an overall trend to reduce pesticide risk.

\section{CPO Contamination in Mill}

Palm oil mills normally receive FFB for processing from their own plantations, private estates or smallholders, who are obliged to deliver crop within $24 \mathrm{hr}$ according to the MPOB guidelines on crop quality. The off-quality crop should be rejected by mills. After weighing the crop, it is subjected to a rigorous grading for quality inspection, the results of which are submitted to the estate management for corrective action. The oil palm mill is used as a processing entity for the $\mathrm{CPO}$ production from palm fruit bunches. As a food product, it is imperative that Hazard Analysis Critical Control Point (HACCP) should be carried out to demonstrate food safety compliance based on the following factors:

Microbiological. This factor can be ruled out because the temperature of the crude oil during processing typically exceeds $90^{\circ} \mathrm{C}$, at which temperature all microbes normally associated with palm fruit are expected to be completely inactive.

Chemical. This is only possible in the form of hydrocarbon originating from petroleum grease that may accidentally spill into fruit elevators and conveyors during greasing operation, thus contaminating fruits. Even though the chances are remote, mills are obliged to isolate the grease points well away from fruit conveyors/elevator under MPOB CoPM so that the grease does not contaminate the CPO. As part of the MPOB CoPM certification requirements, $\mathrm{CPO}$ samples are also sent to an accredited laboratory for pesticide residue and hydrocarbon analysis based on the risk assessment. Any grease used must be food grade.

Physical. This type of contamination can be completely ruled out, such as glass, stones, sand, etc. because pure oil from the clarification tank is pumped into the storage tank after passing through the purifier and vacuum dryer and hence, it is impossible for these contaminants to be presence in CPO. The tanks are daily drained of any accumulated water and cleaned on a regular basis according to the prescribed cleaning schedule.

Therefore, among these three factors, chemical contamination has the highest risk.

\section{ENHANCING SUSTAINABILITY IN PALM OIL MILL PROCESS}

Recently, sustainability is the most importance issue in the oil palm industry. Malaysian producers need to ensure the sustainable production of palm oil due to the global demand for sustainable palm oil products in the world market. Sustainability covers three elements: environmental protection, social responsibility and economic practice. According to the Brundtland Commission, sustainable production should meet the needs of the current generations without compromising the ability of future generations to meet their own needs.

The sustainability goal of oil palm includes a few environmental-friendly approaches, whereby the mill needs to minimise the amount of waste produced, such as palm oil mill effluent (POME). During the extraction of $\mathrm{CPO}$ from the fresh fruits, approximately $50 \%$ of the water is POME. It is 
estimated that for $1 \mathrm{t}$ of CPO produced, 5.0-7.5 $\mathrm{t}$ of water eventually became POME (Latif et al., 2003). Therefore, the mills are encouraged to install the biogas trapping or methane avoidance facilities. Ilyana et al. (2015) has stated that the consumption of oil palm wastes as renewable energy resources is strategically practical because it can promote the sustainability of palm oil mill energy supply while minimising the negative impact of energy generation on the environment. The environmental awareness among the management of mill is needed to support the sustainability in the organisation. The organisation also needs to comply with the environmental legislation as they are subject to the regulatory laws of Malaysia (state and federal).

Social sustainability covers human rights, labour rights and corporate governance. This aspect emphasises that the future generations should have the same access to social resources as the current generation. Corporate social responsibility (CSR) is one of the principles of sustainability that is an integral part of the business. Palm oil mills are also obliged to follow the laws and policies that address employee issues, such as OSHA 1994, FMA 1989, Employment Act 1990, Passport Act 1966 and others. The management shall establish an occupational safety and health $(\mathrm{OSH})$ policy and plan, which necessitate that the employee be provided an awareness and training programme, appropriate personal protective equipment (PPE), standard operating procedure (SOP) for handling of chemicals to ensure proper and safe condition at the workplace.

During the MPOB CoPM auditing, some nearmissing cases at the palm oil plant were observed where there was no safety harness at the filling point. It was observed that laboratory personnel sometimes did not wear the appropriate PPE when handling chemicals due to lack of safety awareness. Therefore, the management has to be responsible and provide training to its employees. Annual medical surveillance should also be carried out for workers exposed to hazardous operations. On the other hand, the Children and Young Persons (Employment) Act 1966 stated that the children and young persons shall not be employed or exploited. The minimum age shall comply with local, state, and national legislation. Child means any person who has not completed his $15^{\text {th }}$ year of age while young person means any person who is not being a child but has not completed his $18^{\text {th }}$ years of age (AGC, 2011). However, children working under the supervision of a parent/adult is acceptable if they are involved in a light work that suits to their abilities and does not interfere with their education. Children and young person should also not be exposed to hazardous works.

The third element of sustainability is the economics of investment which is defined as the ability to use the assorted assets and resources of the company to consistently return profit. Both aspects, protection of environment and social responsibility on health and safety of employees, consumers and communities are playing important roles in the global market of palm oil and give a good return to the palm oil industry. This is due to the sustainability issues in the world market and the requirement for imported sustainable palm oil to be certified. Palm oil industry also provides job opportunities for workers as the number of palm oil mills increased over time. In 1990, there were only 261 palm oil mills in operation with a total processing capacity of 42.87 million tonnes FFB per year. The number of palm oil mill had increased by $61.3 \%$ to 421 mills with a total FFB processing capacity of 97.38 million tonnes per year after two decades (Kushairi et al., 2018). The increased number of mill is due to the increasing FFB production and world market demand on palm oil. In 2018, there were 451 operating mills in Malaysia with a total processing capacity of 112.42 million tonnes per year. About 19.52 million tonnes of CPO and 4.86 million tonnes of palm kernel were produced in 2018. Total palm product exports showed an increase from 23.97 million tonnes in 2017 to 24.88 million tonnes in 2018. India, European Union and China are the largest contribution to the export of palm oil in Malaysia (MPOB, 2018).

\section{CONCLUSION}

This article studies the operation of the palm oil mill and the impact of this operation on human health and environmental pollution. Therefore, with increasing focus on sustainable practices, the millers are encouraged to follow the best practices in producing $\mathrm{CPO}$ at the mill. They need to adhere to the food safety regulations to comply with the global food market demand. The implementation of the MPOB CoPM certification scheme is to address food safety requirements, quality, sustainability and traceability and also a witness audit of best practices implemented. Besides that, the MPOB CoPM audit is a learning platform for the industries to obtain international certification like MSPO, RSPO and ISCC. This will help the oil palm industries to implement MSPO in their premises.

\section{REFERENCES}

AGC (2011). Children and Young Persons (Employment) Act 1966. http://www.agc.gov. my / agcportal/ uploads / files / Publications / LOM/ EN / Act $\% 20350 \% 20-\% 20$ Child ren $\% 20$ and $\% 20$ Young $\%$ 20Persons $\% 20 \%$ 28Employment $\% 29 \% 20$ Act\%201966.pdf, accessed on 4 March 2019. 
AGC (2009). Food Act 1983 (Act 281) E Regulations. International Law Book Services. p. 262-290.

Atikah, A; Ramizi, M; Faizal, W M and Hanif, M S (2017). Black smoke elimination via PID controlled co-firing technique at palm oil mill. Int. J. App. Eng. Res., 12(19): 8050-8056.

Balu, N; Azman, I; Norfadilah, H; Nazlin, I; Dayang, N S; Nik, A N I; Noraida, O; Kamalrudin, M S; Nur, A M H and Kushairi, A (2018). Malaysia: 100 years of resilient palm oil economic performance. J. Oil Palm Res. Vol. 30(1): 13-25.

Ilyana, A; Hasrulnizam, W M; Hafidz, M F; Nizam, A R and Fathiyah, A (2015). Sustainability in Malaysian palm oil: A review on manufacturing perspective. Pol. J. Env. Stud., 24(4): 1463-1475.

Jinius, J; Alinah, A R; Jackson, R J and Phua, P K (2001). Management of pesticide use on vegetable production: Role of Department of Agriculture Sabah. Paper presented at the $6^{\text {th }}$ SITE Research Seminar. 13-14 September 2001.

Kushairi, A; Loh, K S; Azman, I; Hishamuddin, E; Meilina Ong-Abdullah; Izudin, Z B; Razmah, G; Sundram, S and Parveez, G K A (2018). Oil palm economic performance in Malaysia and R\&D progress in 2017. J. Oil Palm Res. Vol. 30(2): 163-195.

Kushairi, A; Meilina Ong-Abdullah; Balu Nambiappan; Hishamuddin, E; Vijaya, S; Izuddin, Z B; Razmah, G; Sundram, S and Parveez, G K A (2019). Oil palm economic performance in Malaysia and R\&D progress in 2018. J. Oil Palm Res. Vol. 31(2): 165-194.

Land Trust Alliance (2019). Carbon dioxide, methane, nitrous oxide, and the greenhouse effect. http: / / climatechange.lta.org / get-started / learn / co2-methane-greenhouse-effect/, accessed on 25 February 2019.

Latif, A; Suzylawati, I and Subhash, B (2003). Water recycling from palm oil mill effluent (POME) using membrane technology. Desalination, 157: 87-95.
MPOB (2008). Code of Good Milling Practice for Palm Oil Mills. MPOB, Bangi. p. 11-12.

MPOB (2018). Overview of the Malaysian oil palm industry. http://bepi.mpob.gov.my/images / overview / Overview_of_Industry_2018.pdf, accessed on 4 February 2019.

Parveen, F R; Rajeev, P S; Hakim, I and Norizan, E (2010). Review of current palm oil mill effluent (POME) treatment methods: Vermicomposting as a sustainable practice. Worl. App. Sci. J., 11(1): 70-81.

PORIM (1994). Palm Oil Factory Process Handbook Part 1: General Description of the Milling Process. PORIM, Bangi. p. 1-109.

Reijnders, L and Huijbregts, M A J (2006). Palm oil and the emission of carbon-based greenhouse gases. J. Cle. Pro., 16: 477-482.

Rohaya, M H; Nasrin, A B; Choo, Y M; Ma, A N and Ravi, M (2006). A commercial scale implementation of Rolek ${ }^{\mathrm{TM}}$ palm nut cracker: Techno-economic vialibity study for production of shell-free kernel. J. Oil Palm Res. (Special Issue-April 2006): 153-167.

WHO (2003). Health aspects of air pollution with particulate matter, ozone and nitrogen dioxide. Report on a WHO Working Group. http: / / www.euro.who.int / __data / assets / pdf_ file/0005/112199/E79097.pdf, accessed on 27 March 2019.

Seyed, E H; Mazlan, A W and Nasim, A (2013). The scenario of greenhouse gases reduction in Malaysia. Ren. and Sus. Ener. Rev., 28: 400-409.

Schuster Institute for Investigative Journalism (2012). Indonesia's palm oil industry. https: / / www. schusterinstituteinvestigations.org / indonesiaspalm-oil-industry, accessed on 20 August 2019.

US EPA (2019). Food and pesticides. https:// w ww.epa.gov / safepestcontrol / food-andpesticides, accessed on 15 April 2019. United States Environmental Protection Agency (US EPA). 